\section{Adult Atopic Dermatitis: Less Certainty, More Challenges}

Megna $\mathrm{M}^{1}$, Patruno $\mathrm{C}^{1}$, Balato $\mathrm{A}^{2}$, Napolitano $\mathrm{M}^{3}$, Balato $\mathrm{N}^{1}$

${ }^{1}$ Section of Dermatology, Department of Clinical Medicine and Surgery, University of Naples Federico II, Naples, Italy

${ }^{2}$ Department of Advanced Biomedical Sciences, University of Naples Federico II, Naples, Italy

${ }^{3}$ Dermatology Unit, Department of Medicine and Health Sciences Vincenzo Tiberio, University of Molise, Campobasso, Italy

J Investig Allergol Clin Immunol 2017; Vol. 27(4): 276-277 doi: $10.18176 /$ jiaci.0155

Key words: Adult atopic dermatitis. Persistent atopic dermatitis. Adultonset atopic dermatitis.

Palabras clave: Dermatitis atópica del adulto. Dermatitis atópica persistente. Dermatitis atópica de aparición en el adulto.

\section{To the Editor:}

We read with great interest the recent article by Silvestre Salvador et al [1] concerning the clinical and diagnostic challenges posed by adult atopic dermatitis (AD). We completely agree with the authors that the numerous problems faced by dermatologists and allergologists during the complex diagnostic and treatment process remain unresolved. Indeed, we previously underlined the need for specific and validated diagnostic criteria for adult $\mathrm{AD}$ in order to improve diagnostic accuracy and to gain more detailed and adequate epidemiologic data. Currently, the prevalence of adult $\mathrm{AD}$ is very variable $(0.3 \%-14.3 \%)$ [2] owing to the lack of multicenter studies and of a common and validated diagnostic algorithm. Indeed, traditional diagnostic criteria for AD (Hanifin and Rajka, UK criteria) were developed specifically for children and were therefore not completely adaptable to adult patients, thus leading to reduced specificity and sensitivity $[1,3,4]$. Hence, there is still no clear consensus on the diagnostic work-up that should be performed when evaluating adult patients with $\mathrm{AD}$, especially adult-onset $\mathrm{AD}$, which is often diagnosed by exclusion. Although new treatments will appear in the near future, no standardized international guidelines for treatment of adult AD have been drafted, with the result that therapy varies widely from country to country [5]. We recently performed a thorough review of the literature on systemic drugs for treatment of adult AD and found limited evidence on effectiveness and long-term safety [5]. Moreover, we strongly believe that new investigations should focus on differences between persistent and adult-onset AD and seek approaches that facilitate diagnosis and treatment. In a recent preliminary analysis of 253 Italian adult AD patients [6], of whom 151 $(59.7 \%)$ were affected with persistent disease and $102(40.3 \%)$ had adult-onset $\mathrm{AD}$, we found no significant differences between the 2 groups with regard to family history of AD, skin lesion morphology (an erythematous-desquamative pattern was the most frequent in both groups), and location of skin lesions (the flexures of the upper limbs were the most commonly involved areas, followed by the eyelid/periocular area, hands, and neck). Severe forms tended to be more common in persistent $\mathrm{AD}$ than in adult-onset $\mathrm{AD}(18.5 \% \mathrm{vs}$ $7.8 \%, P<.05)$. No differences were found for comorbidities (cutaneous or systemic), except for hypertension, which was more frequent in adult-onset AD $(13.7 \%$ vs $2.6 \%, P<.05)$. In conclusion, we agree with Silvestre Salvador et al that adult $\mathrm{AD}$, particularly adult-onset $\mathrm{AD}$, is an unexplored disease in which several issues remain unresolved (detailed incidence and prevalence data, diagnostic criteria, clinical forms, and differences in persistent vs adult-onset disease). These issues can only be addressed in multicenter studies and by increasing awareness of $\mathrm{AD}$ among the scientific community.

\section{Funding}

The authors declare that no funding was received for the present study.

\section{Conflicts of Interest}

The authors declare that they have no conflicts of interest.

\section{References}

1. Silvestre Salvador JF, Romero-Pérez D, Encabo-Durán B. Atopic dermatitis in adults: a diagnostic challenge. J Investig Allergol Clin Immunol. 2017;27:78-88.

2. Napolitano M, Megna M, Patruno C, Gisondi P, Ayala F, Balato N. Adult atopic dermatitis: a review. G Ital Dermatol Venereol. 2016;151:403-11.

3. Kulthanan K, Samutrapong P, Jiamton S, Tuchinda P. Adultonset atopic dermatitis: a cross-sectional study of natural history and clinical manifestation. Asian Pac J Allergy Immunol. 2007:25:207-14.

4. Ozkaya E. Adult-onset atopic dermatitis. J Am Acad Dermatol. 2005;52:579-82. 
5. Megna M, Napolitano M, Patruno C, Villani A, Balato A, Monfrecola G, Ayala F, Balato N. Systemic Treatment of Adult Atopic Dermatitis: A Review. Dermatol Ther (Heidelb). 2017;7(1):1-23.

6. Megna $M$, Patruno $C$, Balato $A$, Rongioletti $F$, Stingeni $L$, Balato N; Italian Adult Atopic Dermatitis Study Group. An Italian multicentre study on adult atopic dermatitis: persistent versus adult-onset disease. Arch Dermatol Res. 2017 Apr 21. doi: 10.1007/s00403-017-1739-y. [Epub ahead of print].
1 Manuscript received February 20, 2017; accepted for publication March 16, 2017.

\section{Matteo Megna}

Section of Dermatology, Department of Clinical Medicine and Surgery

University of Naples Federico II

Via Pansini, 5

80131 Naples, Italy

E-mail: mat24@libero.it 